\title{
Chemokine (C-X-C Motif) Ligand 4 Measurement
}

National Cancer Institute

\section{Source}

National Cancer Institute. Chemokine (C-X-C Motif) Ligand 4 Measurement. NCI

Thesaurus. Code C147330.

The determination of the amount of chemokine (C-X-C mofitf) ligand 4 present in a sample. 